\title{
Gender and Climate Change Adaptation Among Rural Households in Nigeria
}

\author{
Chukwuma Otum Ume, Patience Ifeyinwa Opata, and \\ Anthony Nwa Jesus Onyekuru
}

\section{Contents}

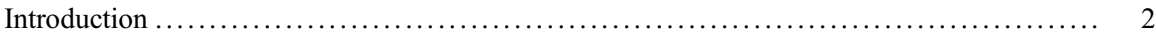

Gender and Vulnerability $\ldots \ldots \ldots \ldots \ldots \ldots \ldots \ldots \ldots \ldots \ldots \ldots \ldots \ldots \ldots \ldots \ldots \ldots \ldots \ldots, \quad 4$

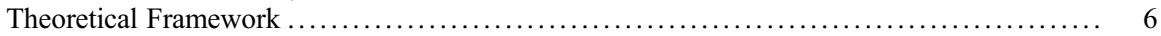

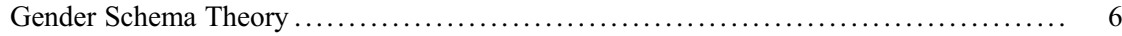

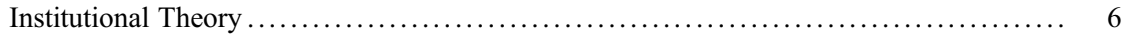

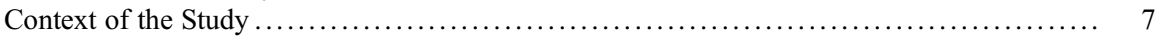

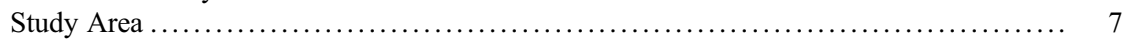

Data Analysis ........................................................... 8

Gender-Vulnerability Differential Among Smallholder Farmers in Nigeria $\ldots \ldots \ldots \ldots \ldots \ldots . \quad 9$

Institutional Factors Undermining Climate Change Adaptation Among Female-Headed

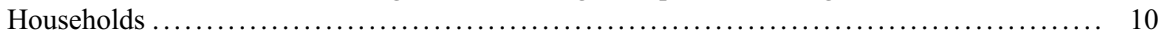

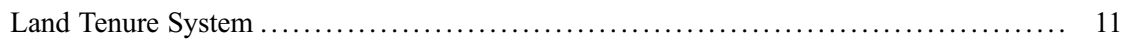

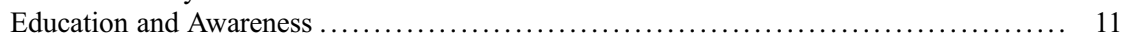

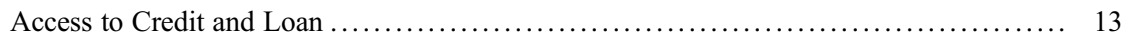

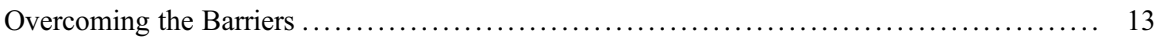

This chapter was previously published non-open access with exclusive rights reserved by the Publisher. It has been changed retrospectively to open access under a CC BY 4.0 license and the copyright holder is "The Author(s)". For further details, please see the license information at the end of the chapter.

C. O. Ume (凶)

Agricultural and Environmental Policy Department, Justus Liebig University Giessen, Giessen, Germany

e-mail: chukwuma.ume@agrar.uni-giessen.de

\section{P. I. Opata}

Department of Agricultural Economics, University of Nigeria, Nsukka, Nigeria e-mail: patience.opata@unn.edu.ng
A. N. J. Onyekuru
Resource and Environmental Policy Research Centre, Department of Agricultural Economics, University of Nigeria, Nsukka, Nigeria
e-mail: anthony.onyekuru@unn.edu.ng 


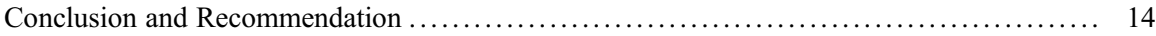

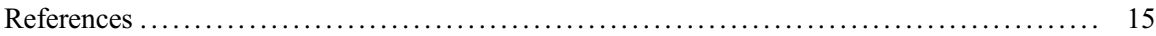

\section{Abstract}

Female- and male-headed rural households have unequal opportunities in climate change adaptation. Efforts in climate change adaptation in regions with deeply entrenched sociocultural norms should also account for the varied gender components of climate change. The broad objective of this study is to integrate gender issues into climate change adaptation thereby distilling lessons and evidence for policymakers on how to approach the necessary transformation of gender relations in climate change interventions. The study employed focus group discussions to uncover the structural factors undermining women's adaptive capacity, thereby making them vulnerable to climate change impacts. In addition to this, indepth interviews were also conducted. For the in-depth interviews, 27 farmers were sampled using a snowballing method, while four focus groups were carried out differently for male and female farmers. Ten extension personnel and ten representations from the ministry of agriculture were also surveyed using indepth interviews. Results from the study showed that female farmers in the region were more vulnerable to climate change as a result of the deeply rooted cultural systems and unwarranted assumptions about women. Findings also suggested that women with high adaptive capacity were less vulnerable to climate impacts. We conclude that gender-responsive climate change adaptation is important in achieving balanced relations that will ensure climate resilience in more equitable and nonhierarchical ways.

\section{Keywords}

Vulnerability · Stereotypes · Gender mainstreaming - Qualitative methods · Socioeconomic status $\cdot$ Nigeria

\section{Introduction}

Climate change is a global phenomenon undermining the efforts towards achieving the Sustainable Development Goals [SDGs]. The Intergovernmental Panel on Climate Change [IPCC] described climate change as the change in global climate patterns which can be identified by variabilities in climate properties over time (IPCC 2014). Climate change has become more threatening not only to environmental quality but also to the fight against poverty, disease, and hunger. This is due to its direct and indirect impacts on agricultural production. While efforts are being made in addressing the causes of climate change through mitigation, building adaptive capacity is particularly important as it will help tackle the current and future impacts of the phenomenon (IPCC 2007). The IPCC defines adaptation as the "adjustment in natural or human systems to a new or changing environment" (IPCC 2007). In other words, climate change adaptation deals with the ability of a system to cushion possible impacts from climate change and to cope with the outcomes. The 
impact of climate change in the developing nations, according to Chukwuemeka et al. (2018), is mostly felt by the smallholder farmers, farmers that are highly dependent on rainwater and other climate-sensitive input and resources.

The vulnerability of these sets of farmers is expected to be even more severe in Nigeria, where majority of women folk are involved in agriculture for household consumption, yet are highly marginalized and excluded in climate decisions which directly affect them (Osuafor and Nnorom 2014). Gender relations in Nigerian agricultural sector have systematically subordinated women, limiting their access to adaptation information and supports (Uchem 2011). Chavez et al. (2011) describes gender as a social construct that portrays the distinction in roles and opportunities associated with the male and female sexes and the social relations between them. Studies on climate change adaptation by farmers in Nigeria have shown that gender relations and women exclusion in climate decisions adversely affect climate change adaptation efforts, as women contribute $60-80 \%$ of food production in the country, mostly for family consumption (Apata 2011; Tersoo 2013; Otitoju and Enete 2016). However, the underlying institutional factors behind these gender issues in Nigeria have not yet been clarified in literature. This gap in literature is what this study intends to fill. Paying attention to these relations is at the core of framing adaptation strategy that will allow farm households build resilience to the impact of climate change in agriculture (MacGregor 2010).

In Africa, literature in climate change adaptation have shown how smallholder farmers suffer high level of vulnerability due to their low adaptive capacity (Okon et al. 2010; Ume 2017). According to FAO (2019), "climate change impact first affects food systems and livelihood groups with a higher level of vulnerability." The IPCC defined climate change vulnerability as the extent to systems, such as geophysical, socioeconomic, and biological systems, which are prone to and incapable of coping with adverse climate change impacts (IPCC 2007). Otitoju and Enete (2016) further noted that among the smallholder farmers in Nigeria, the female farmers are expected to have an even higher level of vulnerability compared to their male counterparts due to their lower adaptive capacities. This, according to them, is due to socioeconomic and institutional factors that undermine their adaptation efforts. According to Eakin and Wehbe (2009), gender transformation - a reassessment of the socioeconomic and institutional factors and relations - established over time, which determines the relationships between the men and women, is therefore imperative if meaningful adaptation effort is to be achieved.

Understanding the gender dimension of climate change adaptation and the underlying socioeconomic factors influencing gender-vulnerability relations among smallholder farmers in Nigeria presents a veritable approach in moving away from the usual incremental adaptation approach to transformational adaptation response. One key importance of transforming gender relations among smallholder farmers is that it is gender that determines the control and ownership of adaptation resources. As stated in FAO (2011), "If women had the same access to productive resources as men, they could increase yields on their farms by $20-30$ percent." Gender analysis among smallholder farmers in Africa is necessary for unraveling how best to mainstream gender issues into climate change adaptation plans and policies. 
The impact of gender relations on farmers' level of adaptation has been extensively reported in the literature. Findings from literature suggest that these gender issues vary from location to location according to levels of socioeconomic developments (Gafura 2017). As stated in Gafura (2017), these socioeconomic and institutional factors are still unsettled issues requiring further study in order to establish a coherent scholarship in the area.

As women make up the majority of the smallholder farm labor force in Africa, the available studies on climate change adaptation among smallholder farmers in Africa such as Komba and Muchapondwa (2015) have highlighted the need for studies that will link information and evidence of the underlying determinants of gender inequality from expert knowledge and farmer's perception, in order to better understand the factors that undermine efforts in coming up with formidable and gender-balanced adaptation policies. More so, the few available studies were based solely on quantitative analysis of household surveys without any qualitative component (Enete and Amusa 2010; Chukwuemeka et al. 2018; Onyeneke et al. 2018). The implication is that since most of the underlying determinants of gender relations cannot be quantified, the results will lack the deep and contextual information needed for the appropriate policy interventions. This perhaps explains why studies on the gender dimensions of climate change adaptation among smallholder farmers in Nigeria have not been able to sufficiently identify and address the gender relations issues impeding climate change adaptation efforts in the country.

\section{Gender and Vulnerability}

The etymology and usage of the word gender show that the concept and its meanings have evolved throughout history. The historical development dates to the late Middle English, when the word was first used to mean "sex of a human being" (Nancy 1989). Recently, it has been conceptualized as a social construct that appropriates certain characteristics such as behaviors, feelings, and attitudes to the male or female individuals in a society (Jrank 2018). What this means is, by knowing a person's gender, we place her or him in a separate social class, and somehow by doing that we judge her or his actions in accordance with our expectations of that social class. According to Jrank (2018), this categorization ultimately leads to the formation of a gendered society - a society with sociocultural expectations of actions deemed appropriate and inappropriate for females and males. This conceptualization led to the emerging theoretical framings on gender roles and stereotypes.

According to Caragliu et al. (2015), gender roles are socially and culturally defined prescriptions and beliefs about the behavior and emotions of men and women. Linda (2017) noted that it is common for different societies to have a set of belief, ideology, and orientation that shapes sociocultural stereotypes among individuals within that society. Caragliu et al. (2015) remarked that it is these gender roles and stereotypes that give rise to the issue of gender identity - a personal perception of oneself which influences her or his status and relationship with other persons in the wider society. Linda (2017) argues that gender roles and stereotypes 
are determined by institutional factors such as rules, norms, and routines, and this consequently affect household interactions so that expectations from members of a household will be based on gender. Therefore, whereas it is traditionally acceptable for the men to have multiple streams of income, in countries like Nigeria, women, who are traditionally perceived as homemakers or housewives, due to stereotype threats, will only make do with farm produce and resources within the homes. According to Linda (2017), this stereotype threat arises as a result of the women's awareness that they are likely to be judged based on an overgeneralized societal belief about her gender roles.

Literature dealing with the influence of gender on vulnerability to climate change impacts follows three mutually exclusive criteria based on IPCC (2007) analysis. These three elements are: exposure (extent of susceptibility), sensitivity (degree of impact), and adaptive capacity (ability to adjust) to climate change impacts. The World Health Organization (2015) noted that female farmers in developing nations are more exposed to climate variabilities mostly because they make up greater percentage of the world's poor and are mostly charged with the responsibility of gathering firewood for heating and cooking, fetching water for domestic chores, and other activities directly linked to the environment. In terms of sensitivity to climate impacts, Mgbenka and Mbah (2016) noted that $80 \%$ of women in many African countries engage in agriculture and are more reliant for their means of support on natural resources that are vulnerable to climate change impacts. Expounding on this fact, Haque et al. (2012) recounted that more than $90 \%$ of the fatalities at the 1991 cyclone in Bangladesh were women, and this was due to their social status, limited skills set, and limited mobility. Finally, in assessing adaptive capacity of femaleheaded households, the RIO+ center in partnership with Food, Agriculture, and Natural Resources Policy Analysis Network conducted a survey in five southern African countries. The results of the survey showed a strong correlation between gender and adaptation level, with women more likely to have low levels of adaptation (Boko 2007). Further analysis showed that women and men in developing nations do not have equal access to climate change adaptation tools in agriculture, with men more likely to have higher access (Onwutuebe 2019). Other studies in various regions in Africa recorded similar results (MacGregor 2010; Ume 2018). Onwutuebe (2019) attributed these gender inequalities to the existing sociocultural norms and institutional factors that limit women's rights and control of resources such as land and financial services. However, none of such studies exploring the role of institutional factors in causing as well as transforming these gender differences have been conducted in Nigeria.

In Africa, studies have also shown that women are highly sidelined in climate decision-making processes, and this in turn affects their access to adaptation information and support in the country (Enete and Amusa 2010; Ume 2018). Enete and Amusa (2010) reviewed journal articles on the influence of socioeconomic characteristics on access to adaptation support in Nigeria in order to ascertain its impact on the agricultural sector of the economy and the implications for economic growth. They noted, in line with RIO+ survey, that gender strongly influences access to support for climate change adaptation in agriculture in the country. Their work 
demonstrated the fact that although agriculture employs over $80 \%$ of the rural populace, Nigeria is the world's third most vulnerable country in terms of the impact of climate change in agriculture. Their main conclusion from the reviewed literature was that the adaptation differential between women and men undermines the capacity of the agricultural sector to absorb climate change multiple stressors and to maintain function in the face of climate change impacts. Similarly, Rammohan (2016) noted that women's lack of adequate access to adaptation support prevents the agricultural sector from evolving into more desirable configurations that build resilience.

\section{Theoretical Framework}

\section{Gender Schema Theory}

Gender schema theory as a perceptive theory attempts to explain the process involved in maintaining and transmitting gender-linked qualities from one generation to another, thereby creating gendered individuals in a community (Kendra 2020). Introduced by Sandra Bem in 1981, the theory shows that sex-linked information is mainly transmitted from one generation to another through "schemata," which is a systematic way of allowing some gender-associated information to be more imbibed by individuals within a society. This information consequently shapes the perception the society has about a particular gender in relation to the other gender, which eventually leads to gender stereotyping. The theory argues that the degree to which individuals become gender-stereotyped is influenced heavily by institutional factors and cultural transmissions such as norms, media, school, home training, etc. By institutional factors, the theory refers to configurations in the society that steers people's behavior (norms, routines, and rules). This means that changing any negative stereotype will involve a transformation of existing norms, rules, and routines.

\section{Institutional Theory}

The institutional theory attempts to explain the process by which societal configurations or social structures (schemas, rules, norms, and routines) become enshrined as authoritative standards guiding social behavior in society (Dobbin and Vican 2015). The theory attempts to unravel how these structures are formed, accepted, and transmitted over time. Dobbin and Vican (2015) argued that these elements of a social structure (norms, rules, and routines) are perceptive and normative elements, that are enforced and endorsed by individuals and organizations which he referred to as "actors" and transmitted by relational systems at different scales and levels. Since they are imposed and upheld by people, they can be altered by affecting changes in the social structures (Dobbin and Vican 2015). The theory suggests that through socialization, better and appropriate institutional elements in the form of cognitive 
orientation can be passed on to individuals and organizations, and when it is adopted, it becomes a new pattern or normal behavior. Over time, these new behaviors become resilient and sediment such that individuals begin to act autonomously without recognizing that they are being controlled by the institution.

\section{Context of the Study}

\section{Study Area}

The study area is Enugu State, Nigeria, that is located in the southeast geopolitical zone of Nigeria. The state was purposively selected because (a) the state is regarded as the capital and policy-making seat of the southeast geopolitical zone, (b) majority of the rural dwellers in this state engaged in small-scale farming, and (c) the state is reported to have experienced marginalization of women in climate change adaptation decision-making (Chukwuemeka et al. 2018). In the national census of 2006, the state has a population of about 3,267,837 (National Bureau of Statistics 2020). Based on the similarities in soil characteristics and by extension meteorological properties, Enugu State is divided into three agricultural zones [AZs]. The zones include Enugu zone, Nsukka zone, and Awgu zone (Fig. 1). The state is in a tropical rain forest zone, with a mean daily temperature of $27^{\circ} \mathrm{C}$ and monthly rainfall of $18 \mathrm{~mm}$ to

Fig. 1 Map of Enugu State showing the three agricultural zones. (Sources:

Chukwuemeka et al. (2018))

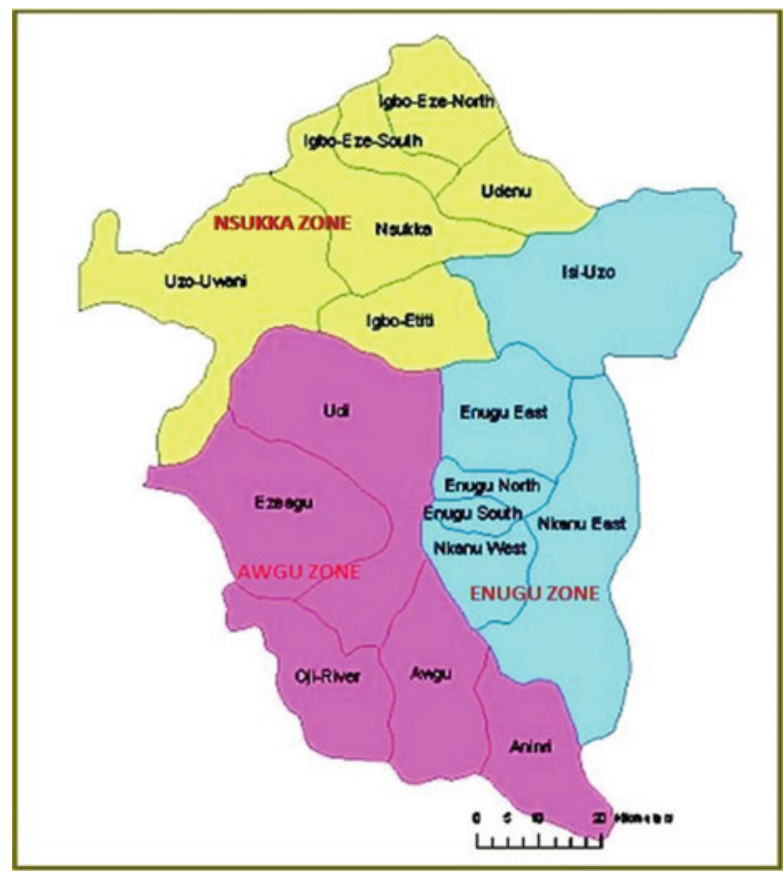


uncover the structural factors undermining women adaptive capacity, thereby making them vulnerable to climate change impacts.

\section{Data Analysis}

Two sets of qualitative data were generated using in-depth interviews and focus groups. Vulnerability analysis technique was employed to analyze the data generated from the interviews, while content analysis was employed to analyze the data generated from the focus groups.

Following Enete and Amusa (2010), we employed the adaptive capacity approach of the vulnerability index analysis to estimate and compare the vulnerability differential between male- and female-headed households in Enugu State, Nigeria. The justification for adopting this approach is based on the assumption that an increasing adaptive capacity (potential adaptation) will lead to a reduction in vulnerability (Enete and Amusa 2010). The measurement of the adaptive capacity of farm households was determined using sets of variables (vulnerability indicators). Results of this analysis are presented in Fig. 2. The variables that formed the adaptive capacity indicators include:

- Income level (farm income)

- Number of extension visit in the last cropping season

- Educational level

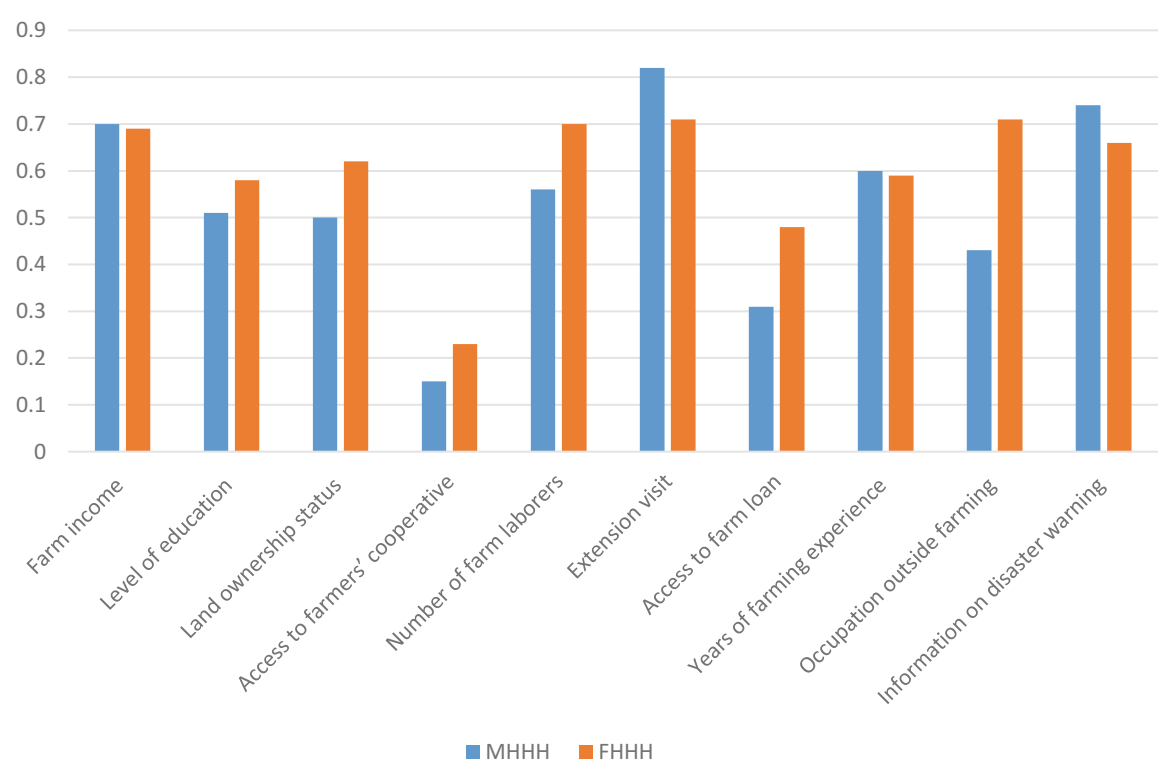

Fig. 2 Gender-vulnerability differential among smallholder farmers in Nigeria 
- Land ownership status

- Years of farming experience

- Membership of cooperative societies

- Number of employees in the farm

- Access to farm loan

- Off-farm activities

- Access to mass media and information on disaster warning

To determine the final index, each of the indicators was normalized so that they will be free from their respective units and lie between $\min =0$ and $\max =1$. Equal weightage values were assigned to each variable and the average was taken as the value for the vulnerability index. We adopted the United Nations Development Programme method of normalizing life expectancy variables in the Human Development Index calculation (UNDP 2007). The normalization was carried out following Hahn et al. (2009) and Tewari and Bhowmick (2014) using the formula:

$$
N S v=\frac{S v-S \min }{S \max -S \min }
$$

where:

$S_{v}=$ value of the component

$N S_{v}=$ normalized value for the component

$S_{\max }$ and $S_{\min }=$ the maximum and the minimum possible values, respectively

By calculating the simple mean of all the variables, the vulnerability index (VI) of all the respondents for the female-headed and male-headed households was determined. To determine the vulnerability index for each gender, we went forward to calculate the mean of the VI for the female-headed households and the male-headed households separately.

The underlining explanation of the gender dimensions in climate change adaptation in Africa can be explained by considering two important theories: gender schema theory and the institutional theory.

\section{Gender-Vulnerability Differential Among Smallholder Farmers in Nigeria}

Using years of farming experience as an indicator of adaptive capacity, the average vulnerability index showed that male-headed households $(0.60)$ are more vulnerable compared to female-headed households (0.59). A discussion with the women in the communities showed that women are inducted into the farming occupation quite at an early age compared to their male counterparts. More farming experience suggests that women are better suited to acquire on-farm experience that will enable them autonomously adapt to climate change impacts. For instance, unlike the male 
farmers, most of the female farmers engaged with could identify several changes in weather patterns they have noticed over the years and how they were able to overcome them. For instance, one of the women stated: "When I was still a youth, working on my mother's farm, we hardly water out maize farms, but now, in other to get a good harvest and fresh grains we do water two or three times in a planting season."

Turning now to off-farm income, female-headed households were found to have a higher vulnerability score. This means that more of the female-headed households rely only on farming for income. We observed that more than half of male-headed households $(60 \%)$ in the study area reported some off-farming activities such as carpentry, palm wine tapping, and material recycling. The high agriculture dependency index of female-headed households (0.71) suggests that the female-headed households might be very sensitive to climate change impacts, as agriculture, being a very volatile and unpredictable enterprise, is subject to total loss once there is a climate event such as flooding, heatwave, or even disease outbreak. Encouraging the women to engage in off-farm activities, therefore, presents a very good way of reducing their vulnerability.

Both the female- and male-headed households had almost the same VI when information on disasters warning is used as an adaptive indicator (Fig. 2). Information gathered from the Agricultural Development Program (ADP) agents indicated that most of the information on disaster warning is normally conveyed through radio stations. Therefore, only women farmers who have radio sets and are close to radio stations, which are mostly located at Enugu zone, can receive information on disaster warnings and weather forecasts.

In general, when all the vulnerability scores were averaged, findings from the analysis, using the adaptive capacity approach, showed that female-headed households in Enugu State, Nigeria, has lower adaptive capacity than their male-headed households. This finding was in line with previous studies such as Amusa (2010). However, we observed a relatively lower vulnerability gap between female- and male-headed households compared to studies such as Amusa (2010). Studies such as Amusa (2010) used the same variables and adaptive capacity indicators employed in this study and reported (female-headed households $=0.73$ and male-headed households $=0.43$ ); however, in this study, we estimated a vulnerability index for the female-headed households $=0.61$ and male-headed households $=0.55$. However, the variation in result reported can be as a result of variation in study area and time when the studies were conducted. The next section attempts to uncover the institutional factors that influence this gender-vulnerability differential.

\section{Institutional Factors Undermining Climate Change Adaptation Among Female-Headed Households}

Most policies and norms that are structured to tackle women's adaptation needs do not address the bigger gender issues. Consistent with the institutional theory, beliefs within the societies have become enshrined as authoritative standards underpinning 
social justice behavior in the society, irrespective of the negative consequences it carries with it. Some of the cultural practices that need to be transformed are discussed below.

\section{Land Tenure System}

This includes the issues of land ownership and transference. From our focus group discussions with the farmers, it was observed that the people hold the belief that if a man dies and he has female and male children, that only the males have the right, by tradition, to possess the family lands. As one of the female farmers stated: "this 3story building you are seeing belongs to my brother and the well here for irrigation is also his, these are what he built from his 'Nsukka pepper' farm which is five times the size of mine, and I must pay rent for my own little piece of land." This is because the culture does not permit women to inherit land, they will resort to renting or saving huge some to purchase their own lands. Scholars in the domain of land reform claim that the main obstacle to climate change adaptation in terms of climate-smart agricultural practices like land rotation, fallowing, etc. is shortage of land and population pressure. However, evidence from our study so far showed that it is not really the shortage of land alone, which affects the adoption of adaptation measures but the structure of land tenure.

Greater population of the farmers in the rural areas are females, but the lack of proper land ownership shifts land title and hence access to the male. Female farmers with both structural and relational access to land have better control and decision on how to put the land to best use. This is predominantly the major problem particularly in most sub-Saharan African countries including Nigeria. The issue of land tenure system, land rights, and climate change adaptation, therefore, presents a very important area that needs to be transformed for better adaptation. Although a strategic gender-responsive and socially inclusive approach can foster a balanced representation of men and women in adaptation initiatives, climate change gender dimensions, and priority to include and empower women and men equally (e.g., by giving them a voice in structural and relations access to land) remain low. Climate change adaptation efforts rest critically on the aspirations and support of those who depend on land-based livelihoods - whose rights and access to land must be protected and promoted for climate change adaptation efforts and initiatives to be sustainable.

\section{Education and Awareness}

Similarly, it was observed that it is normal for parents to send their male children to school instead of their female children. The male farmers interviewed were of the opinion that "the females are "liabilities' but the males are 'assets". According to one of the male farmers, "training my female child in school only for her to get married to another man doesn't benefit me." This shows the level of unjustified 
Fig. 3 Channel of extension visits to households

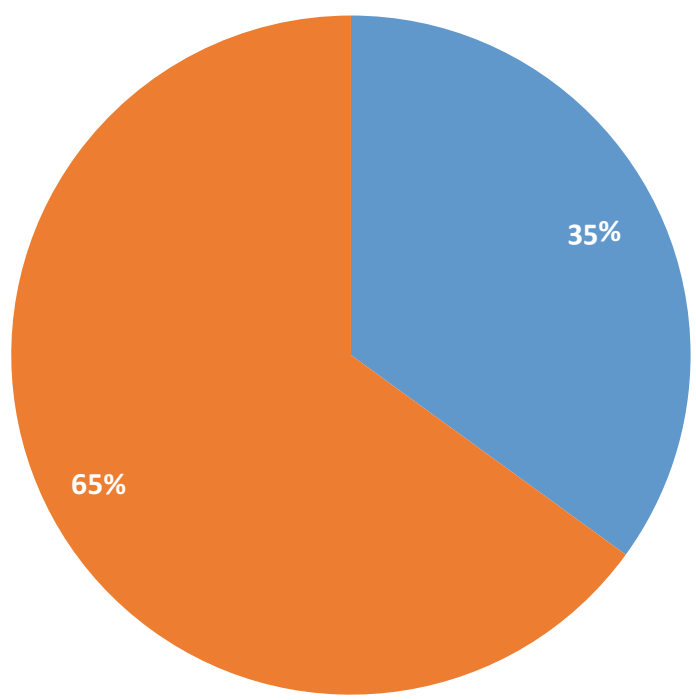

assumption about women. Some of these are the assumptions that women farmers are less informed or intelligent; that some activities are not supposed to be taken up by women; and that women farmers have low self-confidence in taking certain farming decisions. Consistent with the gender-schema theory, these assumptions have been transmitted from one generation to another and have shaped the perception the society has about the female farmers. For instance, it was gathered that extension agents prefer explaining techniques to the male farmers, as they feel they are smarter than their wives, so they can pass the information to their wives. Even the females who oversee the family farms will always project their husband as the household heads, to be better positioned to receive extension services and government aids more easily.

Our study investigated the number of time extension agents visit the female farmers, or gave direct demonstrations to the female farmers, given that extension visits and service delivery helps encourage adaptation. We found that majority of the times $(65 \%)$, most of the contacts were to the male household heads, though the actual farmers are the wives (Fig. 3).

Several studies (Amusa 2010; Apata 2011; Emeana et al. 2018) have shown the positive influence of direct contact in adoption of climate-smart agricultural practices such as zero tillage (Emeana et al. 2018), organic farming (Apata 2011), and increased soil water conservation practices (Amusa 2010). 


\section{Access to Credit and Loan}

The result of our analysis revealed that women who have access to credit and loan facilities had a higher possibility of adaptation to climate change. This is in line with the general literature on credit and small-scale farming in the developing nations. According to Otitoju and Enete (2016), access to credits increases farmers coping capacities and access to more adaptation technologies. Similarly, farm size is as important as capital, and the coefficient of farm size was found to be a statistically significant positive determinant of adaptation. This means that females with larger farm sizes have a higher possibility of adapting (Amusa 2010; Enete and Amusa 2010; Chukwuemeka et al. 2018). This also corroborates the economic constraint paradigm which argues that economic constraints and resource endowments are the key determinants of adoption decision such that lack of access to capital or land could significantly constrain both adoption decisions and extent of adoption (Raihan et al. 2009; Zetterlund 2013).

Literature on micro-financing for smallholder farmers shows that microcredit facilities play a huge role in increasing the level of adoption of climate change adaptation technologies and sustainable land-use practices. Emerging theme from our focus groups shows that there exist functional credit schemes, known as "Akawo Scheme" in the area that supports the farmers with soft loans. Majority of the farmers explained that the scheme offered them loans from which they were able to support themselves in times of crop failures and even to purchase inputs that they will require in their farms. However, we observed that most of the individuals who did not have access to such networks were females. The female farmers explained that because their husbands are members, they are not allowed to take part as well. Most times, the males are not the farmers, so the loans they get are used for other things but aiding their wives on the farm.

\section{Overcoming the Barriers}

We observed two main manners to counter the gender barriers that we illustrated above. First is to improve gender competence and gender training. This means the ability to recognize the social construction and reproduction of gender roles and transform the discriminatory structures and processes. Understanding the gender identities and relations in society will help see the framework conditions provided for women and men, only then can we easily change the perspectives.

Climate change adaptation professionals might be aware of the assessment tools and adaptation strategies; however, they also need to be aware of how they can integrate gender into these strategies and tools in other to acquire gender competence. These can be done in two ways: first is to ensure training on gender and for women. Professionals should be taught on the impact of gender negligence on projects and policy outcomes. Awareness should be raised on how adaptation policies affect men and women differently, making professionals aware of these will have both immediate and long-term impacts. The second is to involve gender 
experts and specialists that can develop gender-sensitive political measures. They will be able to dictate gender lapses in advance and suggest which areas to pay closer attention to.

The second way is to ensure a bottom-top approach to climate change and gender mainstreaming. One important observation is that the women have indigenous adaptation strategies and are in tune with their environment. They adopt autonomously and can provide strategies that are very beneficial for them. However, adaptation policies are often designed through top-down and bureaucratic models. This has two adverse consequences. The first consequence is that the strategies offered to appear as an imposition of external views and knowledge, and thus appear as unnecessary burden to the female farmers, who are supposed to benefit from them. If the females are engaged in policymaking and are allowed to contribute their knowledge, it would certainly lessen the skepticism and opposition toward adaptation. This will make the policies to focus more on inciting and convincing individuals to autonomously integrate climate impacts prevision in their everyday business. The second consequence of the top-bottom approach is that the male counterparts find it easier to receive the knowledge and adaptation technologies when it eventually drops down to the bottom. If the role of adaptation policy is to reduce vulnerability to climate change through the present modification of the behavior of affected actors so that they integrate and anticipate future impacts of climate change, then it is far from an easy task when the women are engaged actively and at all level in conceiving, planning, and executing climate change adaptation policies.

\section{Conclusion and Recommendation}

A gendered perspective on climate change adaptation efforts among smallholder farmers is crucial to sustainable development. This study has added more evidence to the literature on gender and climate change adaptation. Although there appears to be a narrowing of the gender vulnerability gap among smallholder farmers in the area, evidence from this study shows that much work still needs to be done in addressing gender issues in climate change adaptation in Africa, including Nigeria. By taking a gender-sensitive approach, this study highlighted the determinants of adaptation among female-headed households in Nigeria and factors that influence their adaptation to climate change impacts. Furthermore, by incorporating context-specific evidence from the rural farmers, the underlying gender relations and cultural orientations undermining the adaptive capacity of female-headed households were explored. Transforming these gender relations and cultures must form the bedrock for building resilience among farm households in the area. The result of this study shows that cultural systems, policies and practices, and unwarranted assumptions about women are gender relations issues that undermine efforts in building climate change resilience among female-headed households.

Based on the findings from this study, shelving of the identified belief systems that hamper the adaptive capacities of females in the area should be encouraged. It has become obvious that with such societal configurations on the ground, adaptation 
efforts might be jeopardized. In line with the interactionist theory of gender, since gender relations issues are produced by people through interaction, through a deliberate effort by the people, the unwarranted assumption about women and the enshrined belief systems can also be changed.

\section{References}

Amusa TA (2010) Gender and farm household decision on climate change adaptation in southeast, Nigeria. University of Nigeria

Apata TG (2011) Factors influencing the perception and choice of adaptation measures to climate change among farmers in Nigeria. Evidence from farm households in Southwest Nigeria. Available at: https://businessperspectives.org/images/pdf/applications/publishing/templates/arti cle/assets/4402/ee_2011_04_Apata.pdf. Accessed 23 Apr 2020

Boko M (2007) Executive summary Chapter 9: Africa. In: Parry ML et al (eds) Climate change 2007: impacts. London/Cambridge, UK: Cambridge University Press. Print version

Caragliu A et al (2015) Smart cities: transformación digital de las ciudades. In: International encyclopedia of the social \& behavioral sciences, 2nd ed, pp 113-117. https://doi.org/10. 1016/B978-0-08-097086-8.74017-7

Chavez PR et al (2011) Impact of a new gender-specific definition for binge drinking on prevalence estimates for women. Am J Prevent Med 40(4):468-471. https://doi.org/10.1016/j.amepre. 2010.12.008

Chukwuemeka SU, Alaezi K, Ume C (2018) Climate change vulnerability analysis of smallholder farmers in Enugu state Nigeria: gender sensitive approach. J Aridland Agric 4(1):1-6. https:// doi.org/10.25081/jaa.2018.v4.3374

Dobbin F, Vican S (2015) Organizations and culture. In: International encyclopedia of the social \& behavioral sciences, 2nd ed. Elsevier, pp 390-396. https://doi.org/10.1016/B978-0-08-0970868.10453-2

Eakin HC, Wehbe MB (2009) Linking local vulnerability to system sustainability in a resilience framework: two cases from Latin America. Clim Change 355-377. https://doi.org/10.1007/ s10584-008-9514-x

Emeana E, Trenchard L, Dehnen-Schmutz K, Shaikh S (2018) Evaluating the role of public agricultural extension and advisory services in promoting agro-ecology transition in Southeast Nigeria. Agroecol Sustain Food Syst 43(2):123-144. https://doi.org/10.1080/21683565.2018. 1509410

Enete A, Amusa T (2010) Challenges of agricultural adaptation to climate change in Nigeria: a synthesis from the literature. Field Actions Sci Rep 4:1-6. https://journals.openedition.org/ factsreports $/ 678$

FAO (2011) The state of Food and Agriculture 2010-11. Food and Agriculture Organization of the United Nations, Food and Agriculture Organization. Available at http://www.fao.org/ publications/sofa/2010-11/en/. Accessed 23 Apr 2020

FAO (2019) Climate change. Food and Agriculture Organization of the United Nations. Available at: http://www.fao.org/climate-change/en/. Accessed 23 Apr 2020

Gafura AG (2017) Land grabbing, agrarian change and gendered power relations: the case of rural Maasai women of Lepurko village, Northern Tanzania

Hahn MB, Riederer AM, Foster SO (2009) Climate change and human health literature portal the livelihood vulnerability index: a pragmatic approach to assessing risks from climate variability and change - a case study in Mozambique. Glob Environ Change 19(1):74-88. https://doi.org/ 10.1016/j.gloenvcha.2008.11.002

Haque U et al (2012) Reduced death rates from cyclones in Bangladesh. Bull World Health Organ 90(2):150-156. https://doi.org/10.2471/BLT.11.088302 
IPCC (2007) Annex B. Glossary of terms. Intergovernmental Panel on Climate Change. Available at: https://archive.ipcc.ch/pdf/glossary/en.pdf. Accessed 22 Apr 2020

IPCC (2014) Who is who in the Intergovernmental panel on climate change. World Meteorological Organization Building. Switzerland

Jrank (2018) Sex roles - sex-role stereotypes, sex-role socialization - attitudes and behavior, emotional development, Lawrence Kohlberg, and considered - JRank articles. Available at: https://psychology.jrank.org/pages/575/Sex-Roles.html. Accessed 23 Apr 2020

Kendra C (2020) Gender schema theory and roles in culture. Available at https://www. verywellmind.com/what-is-gender-schema-theory-2795205. Accessed 23 Apr 2020

Komba C, Muchapondwa E (2015) Adaptation to climate change by smallholder farmers in Tanzania. Environment for Development Initiative. Available at http://www.jstor.org/stable/ resrep 15022

Linda L (2017) Gender roles: a sociological perspective - Linda L Lindsey. Google Books. Available at https://books.google.de/books?hl=en\&lr=\&id=qjjbCgAAQBAJ\&oi=fnd\& $\mathrm{pg}=\mathrm{PP} 1 \& d \mathrm{dRF} 1 \_\mathrm{Sxf93} \mathrm{pCuL} 46 \mathrm{fbuqUdbA} 4 \&$ redir_esc $=\mathrm{y} \# \mathrm{v}=$ onepage $\& \mathrm{q}=$ genderroles $\&$ $\mathrm{f}=$ false. Accessed 23 Apr 2020

MacGregor S (2010) "Gender and climate change": from impacts to discourses. J Indian Ocean Reg 6(2):223-238. https://doi.org/10.1080/19480881.2010.536669

Mgbenka RN, Mbah EN (2016) A review of smallholder farming in Nigeria: need for transformation. Int J Agric Ext Rural Dev Stud 3(2):43-54. Available at http://www.eajournals.org/wpcontent/uploads/A-Review-of-Smallholder-Farming-In-Nigeria.pdf

Nancy C (1989) Feminism and psychoanalytic theory by Nancy Chodorow: Amazon.com: Books. Available at: https://www.amazon.com/Feminism-Psychoanalytic-Theory-Chodorow. Accessed 23 Apr 2020

National Bureau of Statistics (2020) Pverty statistics. Available at: https://nigerianstat.gov.ng/ elibrary?queries[search] =poverty. Accessed $23 \mathrm{Feb} 2020$

Okon U, Enete A, Bassey N (2010) Technical efficiency and its determinants in garden egg (Solanum spp) production in Uyo Metropolis, Akwa Ibom State. Field actions science reports. J Field Actions 1(1). Available at: https://journals.openedition.org/factsreports/458

Onwutuebe CJ (2019) Patriarchy and women vulnerability to adverse climate change in Nigeria. SAGE Open. 9(1):215824401982591. https://doi.org/10.1177/2158244019825914

Onyeneke RU et al (2018) Status of climate-smart agriculture in Southeast Nigeria. GeoJournal 83 (2):333-346. https://doi.org/10.1007/s10708-017-9773-z

Osuafor A, Nnorom N (2014) Impact of climate change on food security in Nigeria. Affrev Stech 3:208-219

Otitoju MA, Enete AA (2016) Climate change adaptation: uncovering constraints to the use of adaptation strategies among food crop farmers in South-west, Nigeria using principal component analysis (PCA). In: Tejada Moral M (ed) Cogent food \& agriculture, vol 2(1). Informa UK Limited. https://doi.org/10.1080/23311932.2016.1178692

Raihan S, Fatehin S, Haque I (2009) Access to land and other natural resources by the rural poor: the case of Bangladesh. MPRA paper. University Library of Munich, Munich

Rammohan A (2016) Food and nutrition security within the household: gender and access. In: Routledge handbook of food and nutrition security (pp. 368-378). Routledge

Tersoo P (2013) Agribusiness as a veritable tool for rural development in Nigeria. Mediterr J Soc Sci 4(8):17. Available at: https://www.mcser.org/journal/index.php/mjss/article/view/1755

Tewari HR, Bhowmick PK (2014) Livelihood vulnerability index analysis: an approach to study vulnerability in the context of Bihar. J Disaster Risk Stud, 6(1):1-13. Available at: https:// journals.co.za/content/jemba/6/1/EJC163446

Uchem R (2011) Gender roles of men and women in Nigeria and in the United Kingdom. https:// doi.org/10.13140/RG.2.1.2611.3527

Ume C (2017) Critical perspective on climate change adaptation among farmers in developing nations: unpacking divergent approaches. Mod Concepts Dev Agron 1(1). https://doi.org/10. 31031/mcda.2017.01.000504 
Ume C (2018) Critical perspective on climate change adaptation among farmers in developing nations: unpacking divergent approaches. Modern Concepts \& Developments in Agronomy 1 (1):1-6. https://doi.org/10.31031/mcda.2017.01.000504

UNDP (2007) Human Development Report 2007: Fighting climate change - Human solidarity in a divided world. New York. http://hdr.undp.org/en/content/humandevelopment-report-20078

World Health Organization (2015) Gender, climate change and health. World Health Organization. Available at: https://www.who.int/globalchange.pdf. Accessed 23 Apr 2020

Zetterlund Y (2013) Gender and land grabbing - a post-colonial feminist discussion about the consequences of land grabbing in Rift Valley Kenya. Available at: http://dspace.mah.se/dspace/ handle/2043/15718

Open Access This chapter is licensed under the terms of the Creative Commons Attribution 4.0 International License (http://creativecommons.org/licenses/by/4.0/), which permits use, sharing, adaptation, distribution and reproduction in any medium or format, as long as you give appropriate credit to the original author(s) and the source, provide a link to the Creative Commons license and indicate if changes were made.

The images or other third party material in this chapter are included in the chapter's Creative Commons license, unless indicated otherwise in a credit line to the material. If material is not included in the chapter's Creative Commons license and your intended use is not permitted by statutory regulation or exceeds the permitted use, you will need to obtain permission directly from the copyright holder.

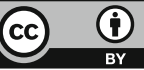

